\title{
Turunçgil Ekstraktı Anti-Giardial Terapötik Destek Sağlayabilir mi?
}

\author{
Deniz ALIÇ URAL ${ }^{1 a ®}$, Songül ERDOĞAN²b ${ }^{2 b}$ Canberk BALIKÇI' ${ }^{3 c}$, Adnan AYAN $^{4 d}$, \\ Hasan ERDOĞAN ${ }^{2 e}$, Kerem URAL ${ }^{2 f}$
}

1. Aydın Adnan Menderes Üniversitesi, Veteriner Fakültesi, Fakülte Çiftliği, Aydın, TÜRKiYE.

2. Aydın Adnan Menderes Üniversitesi, Veteriner Fakültesi, İç Hastalıkları Anabilim Dalı, Aydın, TÜRKiYE.

3. Harran Üniversitesi, Veteriner Fakültesi, İç Hastalıkları Anabilim Dalı, Şanlıurfa, TÜRKiYE.

4. Van Yüzüncü Yıl Üniversitesi, Veteriner Fakültesi, Genetik Anabilim Dalı, Van, TÜRKiYE.

ORCID: 0000-0003-1153-3489 ${ }^{a}$, 0000-0002-7833-5519 - ${ }^{\mathrm{b}}, 0000-0001-7473-5163-{ }^{-}, 0000-0003-1867-{ }^{d}, 0000-0001-5141-5108^{-e} 0000-0003-$ $1867-7143^{-f}$

\begin{tabular}{ccc}
\hline $\begin{array}{c}\text { Geliş Tarihi/Received } \\
22.09 .2020\end{array}$ & Kabul Tarihi/Accepted & Yayın Tarihi/Published \\
20.03 .2021 & 31.10 .2021 \\
\hline Bu makaleye atıfta bulunmak için/To cite this article: & \\
Alıç Ural D, Erdoğan S, Balıkçı C, Ayan A, Erdoğan H, Ural K: Turunçgil Ekstraktı Anti-Giardial Terapötik Destek Sağlayabilir \\
mi?. Atatürk Üniversitesi Vet. Bil. Derg., 16(2): 149-154, 2021. DOI: 10.17094/ataunivbd.798450 \\
\hline
\end{tabular}

Öz: Bu araştırmada turunçgil ekstraktının, giardiasisli oğlaklardaki sağaltım etkinliğinin araştırılması amaçlandı. Bu kapsamda araştırmaya 12-68 günlük yaş aralığında Giardia duodenalis ile enfekte olduğu belirlenen 18 oğlak dahil edildi. Oğlaklar hiçbir ilaç uygulamasının yapılmadığı, kontrol grubu $(n=8)$ ve $10 \mathrm{ml} /$ hayvan başına dozda 7 gün boyunca turunçgil ekstraktının uygulandığı grup $(n=10)$ olacak şekilde rastgele 2 gruba ayrıldı. Turunçgil ekstraktının anti-giardial terapötik etkisi, 0. ve 10. günlerdeki dışkının mikroskobik incelemesindeki ookist saçıımı ile belirlendi. Onuncu gündeki turunçgil ekstraktının terapötik etkinliğinin kontrol grubuna göre \%99.9 olduğu ortaya çıkarıldı. Sonuç olarak ookist saçılımındaki kuvvetli azalma, turunçgil ekstraktının anti-giardiyal etkinliğini desteklemekte ve giardiazis sağaltımında alternatif olabileceğini göstermektedir.

Anahtar Kelimeler: Giardia, İshal, Küçük ruminant, Sağaltım, Turunçgil ekstraktı.

\section{May Citrus Extract Provide Anti-Giardial Therapeutic Efficacy?}

Abstract: In this study, it was aimed to investigate the therapeutic efficacy of the bitter orange extract in goat kids with giardiasis. A total of sixteen goat kids detected to be infected with Giardia duodenalis at the age of 12 to 68 days were enrolled in the study. Goat kids were randomly assigned into two groups, whereas goat kids in the control group $(n=8)$ without receiving any drug and group $(n=10)$ received oral bitter orange extract at a dosage of $10 \mathrm{ml} /$ goat kids for seven days. Antigiardial therapeutic efficacy of bitter orange extract was determined by oocyst shedding interpreted with a microscopical examination of fecal samples on days 0 and 10. It was revealed that the therapeutic efficacy of orange bitter extract as compared with control was $99.9 \%$ on day 10 . In conclusion, this significant decrease of oocyst shedding supports the antigiardial activity of bitter orange extract and shows that it might be an alternative in the treatment of giardiasis.

Keywords: Citrus extract, Diarrhea, Giardiasis, Small ruminant, Treatment.

\footnotetext{
QDeniz Alıç Ural

Aydın Adnan Menderes Üniversitesi, Veteriner Fakültesi, Fakülte Çiftliği, Aydın, TÜRKiYE.

e-posta: alicdeniz@gmail.com
} 
GiRiş

B üyüyen ekonomide keçi yetiştiriciliğinin popülerliği, insan besin zincirindeki rolü sebebiyle gün geçtikçe artmaktadır (1). Paraziter enfestasyonlar ve hastalıkların görülme sıklığı keçi işletmelerinde ekonomik büyümede en önemli kısıtlayıcı unsur olarak karşımıza çıkmaktadır (2). Özellikle paraziter hastalıklar ishale sebep olan ya da verim kaybına neden olan klinik formlarından dolayı keçi yetiştiriciliğini ekonomik olarak etkilemektedir $(3,4)$.

Bu bağlamda zoonotik potansiyeli ile Cryptosporidium spp. ve Giardia duodenalis, insanlar, evcil hayvanların ve vahşi yaşamın en yaygın enterik parazitleri arasında bulunmaktadır (5). Düşük gelirli ülkelerde pediatrik ishalin en yaygın etiyolojik etkenlerinden ikisi ve bu yaş grubunda morbiditenin yanı sıra yüksek mortaliyle de ilişkili olarak karşılaşıldığı bildirilmektedir (6). Az gelişmiş topluluklarda yaşayan insanlarda giardiazis ve cryptosporidiozis'in yüksek prevalansı göz önüne alındığında, bu hastalıklar 2004 yılında WHO tarafından "ihmal edilen hastalık girişimine" dahil edildiği bildirilmektedir (7).

Giardiazisin geleneksel sağaltımında nitroimidazol, benzimidazol, paromamisin, nitazoksanid kullanılabilmektedir (8). Günümüzde ilaçlara karşı artan direnç gelişimi ve hastalıkların gelişme sıklı̆̆ı özellikle doğal bileşenlere olan eğilimi arttırmaktadır $(9,10)$. Bu bağlamda turunçgillerin aslen Güney Çin, Kuzey Doğu Hindistan ve Güney Asya kökenli bir meyve sınıfı olduğu bilinmektedir (11). Yapraklarından veya meyve kabuklarından elde edilen ekstraktların, lokman hekimliğinde (fitoterapi) çeşitli rahatsızlıkların sağaltımında kullanıldığı bilinmektedir (11). Turunçgillerin çeşitli ekstraktlarından yapılan araştırmalarda antiosteoporotik (12), antifungal, anti-aflatoksijenik (13), antioksidan (14) ve antibakteriyel (15) etkilerinin olduğu görülmektedir. Yine benzer şekilde bahsi geçen ekstraktların çeşitli anti-paraziter etkileri de bildirilmiştir (16). Bu sebeple araştırmamızda turunçgil ekstraktının oğlaklarda doğal yolla oluşan giardiazise karşı terapötik etkinliğinin belirlenmesi amaçlandı.

\section{MATERYAL ve METOT}

\section{Çalışma Grupları ve Kompozisyonu}

Çalışmamız Ege Bölgesi Aydın ilinde az sayıda yetiştiricilik yapan bir keçi işletmesinde gerçekleştirildi. Diyaresi bulunan 33 oğlak içerisinden, 18 oğlak çalışma kapsamına alındı. Bu bağlamda değerlendirilen toplamda 18 oğlağın her iki cinsiyette (11 dişi ve 7 erkek), 12-68 günlük yaş aralı̆̆ında olduğu kayıt edildi.

Çalışma kapsamına alınan olgular giardiazis ön tanısına ilişkin saha koşullarında $G$. duodenalis, Coronavirus, Rotavirus, Cryptosporidium ve E. coli K99 sp. antijenlerinin tespitine yönelik ticari test kitlerinden yararlanıldı. ilgili test kitinin her $100 \mathrm{ml}$ dışkı başına 125 kist ve üzerini belirleyebilme kapasitesi göz önünde bulundurularak, pozitif çıkan tüm hayvanların yanı sıra diğer olgularda da çalışma ekibinde yer alan uzman parazitolog eşliğinde dışkı sürme preparatları mikroskobik muayeneye tabi tutuldu. 33 ishalli oğlaktan yalnızca giardiazis ile mono-enfekte olan 18 oğlak çalışma kapsamına alındı. Yukarıda belirtilen diğer etkenlerle enfekte olan ya da G. duodenalis ile ko-enfekte olan $15^{\prime}$ i çalışmaya dahil edilmedi.

Araştırma dahilinde işletme sahibinden bilgi onam formu doldurularak çalışma izni alınmakla birlikte ilgili Etik Kurul onayı [ADÜ-HADYEK no: 64583101/2021/017] mevcuttur.

\section{Gruplara Ayrıştırma}

Giardiazisli oğlaklar kontrol grubunda 8, turunçgil ekstraktı uygulanan grupta 10 olacak şekilde rastgele iki ayrı gruba ayrıldı. Illk gruptaki oğlaklara herhangi bir ilaç uygulaması yapılmadı. 
Buna karşın II. gruba gliserol ve sodyum klorür içeren ticari turunçgil ekstraktı (AuraCalf Auranta, İrlanda; Türk tarafı distribitörü İnterhas Ltd. Şti., Ankara, Türkiye) oral yolla $10 \mathrm{ml} /$ hayvan dozda 7 gün uygulandı. Turunçgil ekstraktı içeren solüsyon sulandırılmadan orogastrik sonda aracılığıyla uygulandı. Yem katkı maddesi uygulama bütünlüğü sırasında çalışmada yer teşkil eden akademisyenlerin hepsi değişimli ve dönüşümlü günlük devir daim ile işletmeye ziyarette bulunarak, uygulamalarda bizzat kendileri rol teşkil etmişlerdir. Çalışma sonunda $G$. duodenalis ile doğal enfekte olan ve çalışma boyunca sağaltım girişiminde bulunulmayan kontrol grubunda, etken üzerindeki sağaltım etkinliği çalışmalarla ortaya konulmuş olan tek doz seknidazol (30 mg/kg/gün, oral) (17-19) ile sağaltım protokolü uygulandı.

\section{Dışkı Analizleri}

Araştırmanın ilk günü (0. gün) ve bitişinde (10. gün) dışkıda Giardia sp.'ye ait kist ve trofozoitlerinin saptanmasına yönelik olarak özellikle uzman parazitolog veteriner hekim her bir dışkı numunelerine ikişer adet ince yayma froti düzenleyerek, Giemsa ile boyandı. Oğlaklarda turunç ekstraktı sağaltım etkinliği 0 . ve 10 . günlerde rektumdan direkt rektal tuşe ile elde edilen dışkı numunelerinin mikroskobik muayenesiyle saptandı. Elde edilen dışkı numuneleri önceki çalışma baz alınarak (9) aynı metodoloji eşliğinde $\times 40$ veya $\times 100$ büyütmede gram dışkı kist sayısına yönelik değerlendirildi. Kist saçılımındaki değişim geometrik ortalamanın Henderson Tilton formülüne aktarımı ile analize edildi.

\section{İstatistiksel Analiz}

Dışkı örneklerinden elde edilen verilerin istatistiksel değerlendirmesinde gruplarda bulunan hayvanlara ait dışkı sayılarının geometrik ortalamaları belirlenerek tabloda sunuldu. Verilerin dağılımları incelendiğinde normal dağılım göstermediği ve logaritmik transformasyon işlemi sonrasında da normalitenin sağlanmadığı belirlendi.
Bu kapsamda gruplar arasında belirtilen günlerdeki ookist sayılarının karşılaştırılmasında Mann-Whitney $U$ analizinden, her bir grubun kendi içerisindeki ookist sayısının günlere göre değişimleri ise Wilcoxon testinden yararlanılarak gerçekleştirildi. Tüm analizlerde SPSS 22.0 (IBM, Amerika) programından yararlanılarak 0.05 değerinin altı istatistiksel anlamlı kabul edildi.

\section{BULGULAR}

Oğlaklarda turunçgil ekstraktının sağaltım etkinliği 0 . ve 10 . günlerde rektumdan direkt olarak toplanan dışkı numunelerinin mikroskobik muayenesindeki kist sayısına göre ele alındı. Gram dışkıda kist atılımı değerlendirildiğinde turunçgil ekstraktının 10. gündeki kist atılımındaki etkinliği \%99.9 olarak belirlendi $(\mathrm{P}<0.005)$. Diğer taraftan kontrol grubunda 0. gün ile (183657.90) 10. günlerde (187971.77) kist atılımları arasında istatistiksel bir farklılık görülmedi (Tablo 1).

Tablo 1. Dışkı ookist sayısındaki değişimler (Geo Ort). Table 1. Changes in the number of fecal oocytes (Geo Mean).

\begin{tabular}{cccc}
\hline & $\begin{array}{c}\text { Ookist } \\
\text { 0. gün }\end{array}$ & $\begin{array}{c}\text { Ookist } \\
\text { 10. gün }\end{array}$ & $\begin{array}{c}\text { \% kist } \\
\text { atılımı }\end{array}$ \\
\hline Kontrol & 183657.90 & $187971.77^{\mathrm{a}}$ & \\
Tedavi & 163126.68 & $2.1^{\mathrm{b}}$ & $\% 99.9$ \\
\hline $\mathrm{a} ; \mathrm{P}>0.05 \mathrm{~b} ; \mathrm{P}<0.005$. & &
\end{tabular}

\section{TARTIŞMA ve SONUÇ}

$\mathrm{Bu}$ çalışmada doğal yolla giardiazis tanısı konulan oğlaklarda oral ticari turunçgil ekstraktı içeren solüsyonun anti-giardial etkisi ve ookist saçılımını nasıl etkilediğinin ortaya konulması amaçlandı.

Çalışma kapsamına alınan oğlaklarda turunçgil ekstraktının gram dışkıda kist atılımını \%99.9 etkinlikle azaltması oldukça tatmin edici bulundu. Diğer yandan kontrol grubunda 0. gün ile (183657.90) 10. günlerde (187971.77) kist atılımları arasında istatistiksel bir farklılık görülmedi.

Giardiazisin ruminantlarda yüksek prevalansa sahip olmasının beraberinde olası verim kayıpları, ek olarak zoonoz hastalık riski nedenleriyle aciliyet gerektirecek nitelikte sağaltılmasının uygun olacağı 
bildirilmektedir $(20,21)$. Ruminantlarda giardiazis sağaltımında fenbendazol (22), albendazol (23), ya da paramomisin (24) öne çıktığı bildirilmektedir. Bununla birlikte antimalarial bir ajan olan klorokinin son dönemlerdeki ek sağaltım seçenekleri arasında yer alabileceği belirtilmiştir $(20,21)$. Hem sağaltımda yetersiz miktarda seçeneğin bulunması, hem de mevcudiyeti olan ajanların giardiazis sağaltımı amaçlı FDA onayı bulunmaması gibi tüm sebeplerden dolayı yeni sağaltım seçenekleri umut vaat edebilir (25). Hatta bizim çalışmamızda yer verildiği üzere nutrasötiklerin (tercih sebebimiz turunçgil ekstraktı) ve alternatif diğer doğal yem katkı maddelerinin farklı hastalıklara yönelik sınırlı sayıda araştırma olsa bile gelecek vadettiği öne sürülebilinir. Güçlü antiinflamatuvar, antimikrobiyel ve antioksidan aktiviteleri ile turunçgil ekstraktı enflamasyon kaynaklarını kısıtlayarak, muhtemelen de vücudun doğuştan sahip olduğu kendi kendini iyileştirme yeteneğini arttırabilir. Basit reçete (doğal ürünler) Dr. Perlmutter'in Tahıl Beyin kitabında bahsettiği gibi ilaç ile sağaltıma galip gelebilir. Bu bağlamda çalışmadan elde edilecek sonuçlar geleceğe ışık tutabilme potansiyeline sahiptir. Yüksek kalitede polifenol ve flavanoid içerebilen turunçgil meyveleri mitokondriyel biyogenezis ile ilişkilendirilmekte (26) muhtemelen de ileride mitokondriyel tıp alanında daha da önemli yere sahip olabilecektir.

Aslen Güney Çin, Kuzey Doğu Hindistan ve Güney Asya kökenli, rutaceae bitki familyasına ait turunçgiller (11) mutfak, içecek, endüstriyel ve tıbbi alanda yaygın olarak kullanılmaktadır. Ekşimsi tada sahip meyvelerinde $\mathrm{C}$ vitamini içeriği yüksek olup antioksidan etkinliğiyle hücresel hasarı önlemekte ve bağışıklık sistemini güçlendirmektedir (14). Ayrıca antimikrobiyel ve etkinliği iyi bildirilmektedir (15). Belirtildiği gibi turunçgil ekstraktı farklı özellikleri ile hayvan yetiştiriciliğinde yem katkı maddesi olarak kullanılabilmekte ve verim artışı üzerinde olumlu etkilerinin olduğu görülmektedir (27).

Bunların dışında, ishale neden olan bazı etkenlere karşı etkinliği ve antimikrobiyel özelliklerinin bulunması avantajdır $(15,28)$. In vitro olarak Entamoeba histolytica ve Giardia lambia etkenlerine (28), tavuklarda Ascaridia galli adlı paraziter etkene (29) karşı etkin şekilde kullanımı, çalışmamızın sonuçlarını da destekler niteliktedir.

Genel olarak turunçgil ektraktının yukarıda geniş kapsamlı bahsedilen antiinflamatuvar, antimikrobiyel ve antioksidan etkilerinin paraziter gelişimi engellediği düşünülmekle birlikte in vitro hücre kültüründe $G$. lambia üzerindeki etkileriyle benzer olarak etkene ait fenollerin toksikasyonundan sorumlu mekanizması, enzimlerin muhtemelen belirli gruplarla etkileşime girerek veya proteinlerle rastgele etkileşim yoluyla bileşikleri oksitleyen inhibisyonunu içermektedir. Diğer bir olası mekanizma turunçgil ektraktında yoğun şekilde bulunan flavonoidlerin yağlarla benzer etkiyle, etkenin hücre zarında hasar vererek gelişimini engelemesiyle açıklanabilir $(15,26,28)$.

Sonuç olarak bu çalışma ile dışkıdaki ookist atılımının \%99.9 oranında azalması, turunçgil ekstraktının anti-giardiyal etkinliğini desteklemekte ve turunçgil ekstraktının anti-giardial sağaltımda alternatif olabileceğini göstermektedir.

\section{Çıkar Çatışması}

Yazarlar, çıkar çatışması olmadığını beyan eder.

\section{KAYNAKLAR}

1. Pulina G., Milan MJ., Lavin MP., Theodoridis A., Morin E., Capote J., Caja G., 2018. Invited review: Current production trends, farm structures, and economics of the dairy sheep and goat sectors. J Dairy Sci, 101, 6715-6729.

2. Singh DD., Pawaiya RVS., Gururaj K., Gangwar NK., Mishra AK., Singh R. Kumar A., 2018. Detection of Clostridium perfringens toxinotypes, enteropathogenic E. coli, Rota and corona viruses in the intestine of neonatal goat kids by molecular techniques. Indian J Anim Sci, 88, 655-661.

3. Mishra AK., Singh DD., Kumar N., Kumarsen G., Paul S., Kumar A., 2020. Role of Bacterial and Parasitic Pathogens in Occurrence of Neonatal 
Diarrhoea in Goat-Kids. J Anim Res, 10, 389-395.

4. Sargison ND., 2020. The critical importance of planned small ruminant livestock health and production in addressing global challenges surrounding food production and poverty alleviation. N Z Vet J, 68, 136-144.

5. Toledo RDS., Martins FDC., Ferreira FP., de Almeida JC., Ogawa L., dos Santos HLE., Freire RL., 2017. Cryptosporidium spp. and Giardia spp. in feces and water and the associated exposure factors on dairy farms. PloS One, 12, e0175311.

6. Platts-Mills JA., Babji S., Bodhidatta L., Gratz J., Haque R., Havt A., 2015. Pathogen-specific burdens of community diarrhoea in developing countries: a multisite birth cohort study (MALED) Lancet Glob Health, 3, 564-e575.

7. Savioli L., Smith H., Thompson A., 2006. Giardia and Cryptosporidium join the 'neglected diseases initiative' Trends Parasitol, 22, 203-208.

8. Rossignol JF., 2010. Cryptosporidium and Giardia: treatment options and prospects for new drugs. Exp Parasitol, 124, 45-53.

9. Alıç Ural D., Erdoğan H., Toplu S., Ayan A., 2017. Oğlaklarda Giardiazis Kontrolüne Yönelik Oral Klinoptilolit Uygulaması. Kocatepe Vet J, 10, 158163.

10. Riches A., Hart C., Trenholme K., Skinner-Adams TS., 2020. Anti-Giardia drug discovery: Current status and gut feelings. J Med Chem, 25, 1333013354.

11. Wu GA., Terol J., Ibanez V., Lopez-Garcia A., Perez-Roman E., Borreda C., Talon M., 2018. Genomics of the origin and evolution of Citrus. Nature, 554, 311-316.

12. Shalaby NM., Abd-Alla HI., Ahmed HH., Basoudan N., 2011. Protective effect of Citrus sinensis and Citrus aurantifolia against osteoporosis and their phytochemical constituents. J Med Plants Res, 5, 579-588.

13. Nidhi P., Rolta R., Kumar V., Dev K., Sourirajan A. 2020. Synergistic potential of Citrus aurantium L. essential oil with antibiotics against Candida albicans. J Ethnopharmacol, 262, 113135.
14. Falcinelli B., Famiani F., Paoletti A., D’Egidio S., Stagnari F., Galieni A., Benincasa, P., 2020. Phenolic Compounds and Antioxidant Activity of Sprouts from Seeds of Citrus Species. Agriculture, 10, 33.

15. Okla MK., Alamri SA., Salem MZ., Ali HM., Behiry SI., Nasser RA., Soufan W., 2019. Yield, phytochemical constituents, and antibacterial activity of essential oils from the leaves/twigs, branches, branch wood, and branch bark of Sour Orange (Citrus aurantium L.). Processes, 7, 363.

16. Ettebong E., Ubulom P., Etuk A., 2019. Antiplasmodial activity of methanol leaf extract of Citrus aurantifolia (Christm) Swingle. J Herbmed Pharmacol, 8, 274-280.

17. Jimenez JC., Pinon A., Dive D., Capron M., DeiCas E., Convit J., 2009. Antibody response in children infected with Giardia intestinalis before and after treatment with Secnidazole. Am J Trop Med Hyg, 80, 11-15.

18. Ural K., Aysul N., Voyvoda H., Ulutas B., Aldemir OS., Eren H,. 2014. Single dose of secnidazole treatment against naturally occuring Giardia duodenalis infection in Sakiz lambs. Rev MVZ Cordoba, 19, 4023-4032.

19. Da Silva AS., Castro VS., Tonin AA., Brendler S., Costa MM., Jaques JA., Monteiro SG., 2011. Secnidazole for the treatment of giardiasis in naturally infected cats. Parasitol Int, 60, 429432.

20. Gultekin M., Ural K., Aysul N., Ayan A., Balikci C., Akyildiz G., 2016. The efficacy of chloroquine treatment of Giardia duodenalis infection in calves. Vlaams Diergeneeskd Tijdschr, 85, 335341.

21. Karademir U., Ural K., Aysul N., Ayan A., Toplu S., Ortlek O., Balıkci C., Kunyeli A., Erdogan H., 2016. The efficacy of chloroquine treatment against naturally occuring Giardia duodenalis infection in lambs. Rev MVZ Cordoba, 21, 5328-5335.

22. Geurden T., Pohleb H., Sarrea C., Dreesena L., Vercruyssea J., Claerebouta E., 2011. The effcacy of a treatment with fenbendazole against an 
experimental Giardia duodenalis infection in lambs. Small Rum Res, 96, 211-215.

23. Ragbetli C., Tanritanir P., Yilmaz H., Yoruk I., Ozdemir H., 2014. Effect on biochemical parameters in naturally infected calves with giardiasis after treatment with albendazole Van Province, Turkey. Indian J Anim Res, 48, 38-44.

24. Geurden T., Claerebout E., Dursin L., Deflandre A., Bernay F., Kaltsatos V., Vercruysse J., 2006. The efficacy of an oral treatment with paromomycin against an experimental infection with Giardia in calves. Vet Parasitol, 135, 241247.

25. Lalle M., Hanevik K., 2018. Treatment-refractory giardiasis: challenges and solutions. Infect Drug Resist, 11, 1921.

26. Wood dos Santos T., Cristina Pereira Q., Teixeira L., Gambero A., A Villena J., Lima Ribeiro M., 2018. Effects of polyphenols on thermogenesis and mitochondrial biogenesis. Int J Mol Sci, 19, 2757.

27. Paniagua M., Crespo J., Aris A., Devant M., 2019. Citrus aurantium flavonoid extract improves concentrate efficiency, animal behavior, and reduces rumen inflammation of Holstein bulls fed high-concentrate diets. Anim Feed Sci Tech, 258, 114304.

28. Mayaa FAK., Alasadiy YDK., 2015. Effect of cold aqueous plant extract (Citrus aurantium and Solanum melongena) against the Giardia lamblia parasite and Entamoeba histolytica in vitro and measuring the LD50 for extracts in Al-Muthanna province. Res J Pharm Biol Chem Sci, 6, 12411252.

29. Abdelqader A., Qarallah B., Al-Ramamneh D., Daş G., 2012. Anthelmintic effects of citrus peels ethanolic extracts against Ascaridia galli. Vet Parasitol, 188, 78-84. 